\title{
Do Latino and non-Latino grocery stores differ in the availability and affordability of healthy food items in a low-income, metropolitan region?
}

\author{
Jennifer A Emond ${ }^{1,2, *}$, Hala N Madanat ${ }^{2,3}$ and Guadalupe X Ayala ${ }^{2,3}$ \\ ${ }^{1}$ Cancer Prevention and Control Program, UCSD Moores Cancer Center, University of California, \\ 9500 Gilman Drive, La Jolla, San Diego, CA 92093-0901, USA: ${ }^{2}$ Graduate School of Public Health, \\ San Diego State University, San Diego, CA, USA: ${ }^{3}$ San Diego Prevention Research Center, \\ the Institute for Behavioral and Community Health, San Diego, CA, USA
}

Submitted 1 November 2010: Accepted 18 April 2011: First published online 7 July 2011

\begin{abstract}
Objective: To compare non-ethnically based supermarkets and Latino grocery stores (tiendas) in a lower-income region with regard to the availability, quality and cost of several healthy $v$. unhealthy food items.

Design: A cross-sectional study conducted by three independent observers to audit twenty-five grocery stores identified as the main source of groceries for $80 \%$ of Latino families enrolled in a childhood obesity study. Stores were classified as supermarkets and tiendas on the basis of key characteristics.

Setting: South San Diego County.

Subjects: Ten tiendas and fifteen supermarkets.

Results: Tiendas were smaller than supermarkets (five $v$. twelve aisles, $P=0 \cdot 003$ ). Availability of fresh produce did not differ by store type; quality differed for one fruit item. Price per unit (pound or piece) was lower in tiendas for most fresh produce. The cost of meeting the US Department of Agriculture's recommended weekly servings of produce based on an $8368 \mathrm{~kJ}(2000 \mathrm{kcal}) / \mathrm{d}$ diet was $\$$ US $3 \cdot 00$ lower in tiendas compared with supermarkets $(P<0 \cdot 001)$. The cost of 1 gallon of skimmed milk was significantly higher in tiendas (\$US 3.29 v. \$US 2.69; $P=0.005)$ and lean (7\% fat) ground beef was available in only one tienda $(10 \%)$ compared with ten $(67 \%)$ supermarkets $(P=0 \cdot 01)$.

Conclusions: Barriers remain in the ability to purchase healthier dairy and meat options in tiendas; the same is not true for produce. These results highlight the potential that tiendas have in improving access to quality, fresh produce within lower-income communities. However, efforts are needed to increase the access and affordability of healthy dairy and meat products.
\end{abstract}

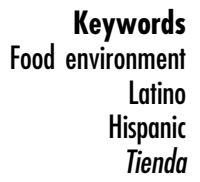

Product availability within grocery stores is an important aspect to be considered in terms of one's ability to purchase healthy food items. The average US consumer makes $2 \cdot 1$ trips/week to buy groceries ${ }^{(1)}$, and store type may influence purchasing behaviour. Differences have been noted in the availability, quality and cost of products in smaller grocery stores as compared with supermarkets in lower-income urban areas. For example, the availability of healthier food alternatives (such as low-fat milk or high-fibre bread) may be limited in smaller grocery stores as compared with supermarkets ${ }^{(2-4)}$, and supermarkets may offer higher-quality produce at lower costs compared with smaller grocery stores ${ }^{(2,3)}$. Cost is of major consideration in food purchasing behaviour ${ }^{(5)}$ and a positive link between affordability of fruit and vegetables and risk of childhood obesity has been observed ${ }^{(6)}$.
Such data support the reported positive relationships between proximity to supermarkets and quality of $\operatorname{diet}^{(7-10)}$. However, beyond the availability of supermarkets or grocery stores within a community, past research has failed to consider where people choose to shop for their groceries and the extent to which this may ultimately influence their accessibility, availability and affordability to healthy foods; the present study attempts to fill this gap.

Considering that Latinos in the USA are at a high risk for obesity ${ }^{(11)}$ and for related comorbid conditions ${ }^{(12,13)}$, and are over-represented in lower-income communities ${ }^{(14)}$, Latinos may face barriers to purchasing healthy food items on the basis of where they do most of their household grocery shopping. Unfortunately, there is limited information on access to healthy foods among Latinos. Previous studies examining access to healthy 
foods did not consider Latino ethnicity ${ }^{(4,15)}$. They were also underpowered ${ }^{(3)}$ or were confounded by regional location ${ }^{(8,9)}$. Even when a supermarket is located within a lower-income community, access to that market might be limited. For example, Latino households are less likely to have access to a vehicle and more likely to rely on public transportation: factors that may influence one's choice to shop at a closer grocery store instead of at a supermarket that might be further away (as summarized in the National Council of La Raza 2010 Profile of Latino Health $)^{(16)}$. Besides proximity, acculturation also appears to influence the choice to shop at a supermarket. Ayala et $a l^{(17)}$ showed that among 357 Latino women in Southern California ( $82 \%$ of Mexican descent), those with lower acculturation scores were more likely to shop in grocery stores than in supermarkets. These grocery stores were mostly Latino grocery stores, or tiendas. Tiendas are often smaller in size compared with supermarkets, yet larger than convenience or corner stores, and are often independently owned ${ }^{(18)}$. The extent to which they represent a supportive or unsupportive food environment is not yet known.

The present study was therefore conducted to examine differential accessibility, availability and affordability of healthy food items within supermarkets compared with tiendas in a lower-income, largely Mexican-origin region of Southern California. An extensive store audit was completed by three independent observers for twentyfive food stores identified as the primary source of household groceries by 528 Latino families. We examined the availability, quality and cost of several fresh fruit and vegetables and computed the cost to meet the recommended weekly servings of fruit and vegetables on the basis of fresh produce per store type. We also compared the availability and cost of a selection of canned and frozen produce and the availability and cost of lower-fat alternatives to milk and ground beef. Disparities in access to quality, healthy food items at an affordable price by store type could have implications on the dietary choices made among Latinos in lower-income communities.

\section{Methods}

\section{Setting}

The present study was conducted in South San Diego County, which is located on the California-Mexico border. This region includes four cities and represents sixty Census tracts and encompasses approximately 300000 residents, $58 \%$ of whom are Latinos ${ }^{(19)}$. Median values of age and household income are 29 years and \$US 37948 , respectively; $67 \%$ of the population has completed high school $^{(19)}$. This differs from the general US population, in which $13 \%$ of residents are Latino, $74 \%$ are between 18 and 65 years of age, the median income is \$US 52029 and $80 \%$ have completed high school or more ${ }^{(20)}$.

\section{Store identification}

Stores considered for store audits were selected from those identified as the primary source of groceries for the family among participants in the 'Aventuras para Niños' (APN) study. As part of the APN study, thirteen schools were invited to participate and randomly assigned to one of four interventional conditions. Parents (primarily mothers) with children in kindergarten through third grade who agreed to participate completed a self-administered survey at baseline, along with measures of height and weight.

Similar to methods used in a previous study ${ }^{(21)}$, parents were asked to provide the name, address and cross street of the store where their family purchased most of their groceries. Using funding obtained 2 years after baseline, the names and addresses of these stores were compared with a store enumeration database that was generated using four sources of data (ReferenceUSA, online Yellow Pages, San Diego Nutrition Network and the San Diego County Department of Health and Human Services). Stores were considered for audits if they were included in this database. Of the 811 families enrolled in the APN, stores were verified for 656 (81\%) families. We excluded warehouse stores ( $n 51)$, commissaries $(n 7)$, dollar stores ( $n 5)$ and stores no longer in existence at the time of the audits ( $n$ 65). A total of twenty-five stores were selected for audits; these stores were reported as the primary source of groceries for 528 (80\%) families enrolled in the APN.

\section{Store audit form}

The audit form was created using the ANGELO (analysis grid for environments linked to obesity) framework ${ }^{(22)}$. This framework emphasizes an understanding of potential physical, economic, political and socio-cultural environmental factors that may contribute to obesity. Five steps are outlined (needs analysis, problem identification, strategy development, intervention and evaluation) to develop successful environmental interventions. Our data represent part of the needs analysis and problem identification steps.

The audit form captured numerous aspects of the store environment, including elements related to the type of store (Latino $v$. non-Latino), cost and quality of fresh fruit and vegetables, the availability and cost of three varieties of ground beef and the availability and cost of three varieties of milk. Observers also noted store characteristics, including the number of checkout stations and the number of aisles per store.

\section{Store type}

During the audit process, stores were classified as nonLatino and Latino on the basis of three characteristics: language that most customers and employees used during the audits (mostly English, mostly Spanish, or both equally), language of signage on the windows and doors (mostly English, mostly Spanish, or both equally) and store name. Importantly, in all but two Latino-classified 
stores, the store name was in Spanish. These methods were more complete than previous categorization methods of ethnic grocery stores based solely on store name ${ }^{(23)}$. Agreement across observers on store classification was 100\%.

Although not a planned aspect of the study design, none of the Latino stores identified were supermarkets; all were independent grocery stores or tiendas. In contrast, all of the non-Latino stores were supermarkets based on the North American Industry Classification System criteria. Thus, we report our findings comparing tiendas with supermarkets.

\section{Fresh produce}

Fifteen fresh fruits and twenty fresh vegetables were included in the audit. These items were included because they were the most frequently reported produce items consumed by members of the target community identified during $24 \mathrm{~h}$ dietary recalls ${ }^{(24)}$. Observers were instructed to: (i) identify whether the product was present or absent during the audit; (ii) rate the quality of each product on a 3-point scale (poor/low, fair/medium and good/high); and (iii) note the cost based on the unit indicated in the study protocol (e.g. one pound of broccoli; one avocado). Quality ratings of poor/low were given if $>50 \%$ of the produce was mouldy, bruised, punctured or covered with flies or dirt. Quality ratings of fair/medium were given if $<25 \%$ of the produce met the poor/low-quality rating. Quality ratings of good/high were given if nearly all or all of the produce did not meet the poor/low criterion. Only observed produce was coded; price signs were not used to assume that a product was generally available but simply out of stock.

\section{Canned and frozen produce}

Although the store audit form was not designed to capture all foods in the US Department of Agriculture's (USDA) Thrifty Food Plan market basket, eleven canned and frozen items were included that could be considered as alternatives to fresh produce as suggested by this plan $^{(25)}$. Therefore, we compared the availability and cost of these items in an effort to determine availability outside of fresh produce. Items were considered available if at least one unit of the product was visible on the store shelf or in the freezer section. The presence of price tags or other shelf labels without visible product was not considered. Included were the following canned items: corn $(15 \cdot 25 \mathrm{oz})$, green beans $(14.5 \mathrm{oz})$, mandarin oranges (11 oz), peaches (in heavy syrup $15 \cdot 25 \mathrm{oz}$ and light syrup $15 \mathrm{oz}$ ) and whole tomatoes $(14.5 \mathrm{oz})$; and the following frozen items: mixed fruit $(1 \mathrm{lb}), 100 \%$ fruit juice $(12 \mathrm{oz}$ can), $100 \%$ orange juice concentrate ( $12 \mathrm{oz}$ can), green beans (1 lb) and peas ( $1 \mathrm{lb})$.

\section{Low-fat alternatives for milk and ground beef}

The dairy section of the audit form captured the availability and cost of three varieties of milk: whole, $2 \%$ and skimmed/fat free. Availability was assessed as the number of facings, and cost was noted per gallon. The presence of price tags or other shelf labels without visible product was not counted. To minimize exaggeration of product availability based on total shelf facings, a facing was counted only if it was at least $50 \%$ stocked. For example, if the depth of the shelf accommodated six, 1-gallon containers, the facing was counted if three or more 1-gallon containers were present in the row. In cases where several facings were $<50 \%$ stocked, individual containers were counted and considered to represent a facing if sufficient product was available as per the above definition.

The meat section of the audit form captured the availability and cost of three varieties of ground beef: regular fat (at the most 30\% fat according to the USDA standards ${ }^{(26)}$ ), 15\% fat (also known as pulpa molida) and $7 \%$ fat. The product was considered available if at least one unit was visible in the display case. Cost was noted per pound for pre-packaged meat; cost did not reflect meat available from in-store butchers given that all stores did not have a butcher section.

\section{Store audit procedures}

Three observers audited each store: two study personnel and the last author (G.X.A.) who led the present study. One of the study personnel and the last author were trained to conduct store audits using the Nutrition Environment Measures for Stores tool ${ }^{(27)}$, and this experience was used to train personnel using the audit form of the present study. Piloting in four stores (not included in this sample) was completed to allow testing and refinement of the audit form until a high rate of reliability was achieved (93\% agreement across all observed items).

Store audits were conducted during a 2 -week period in the summer of 2006. Observations were made by all three observers simultaneously to minimize temporal differences. To minimize obtrusiveness, the three observers travelled throughout the store in different ways so that no single observer was coding the same information at the same time. Permission to conduct the audit was not sought before data collection in order to avoid any interactions with store employees that might impact knowledge of product availability. However, all observers had study information sheets available to share with managers and employees if requested. All scheduled audits were completed.

Consensus coding for each item in each store, including cost, was based on the majority value reported (i.e. at least two-thirds of time). Across all items examined in the present study, $100 \%$ agreement between all three raters was observed for 1640 (74\%) of the 2225 data points; majority agreement was met for 1992 (90\%) of the total 2225 data points. In cases of disagreement, the last author provided the consensus code. Given the high rate of agreement between observers, $\kappa$ values were 
not valid ${ }^{(28)}$. Instead, we estimated inter-rater reliability as the average percentage of agreement across the three observers. Median percentage of agreement was high $(0 \cdot 87)$, with no difference by store type $(P=0 \cdot 434)$. Median percentage of agreement was lowest for milk and beef items $(0 \cdot 67)$, with no difference by store type $(P=0 \cdot 189)$. Agreement was highest for fresh produce cost, with observers in tiendas having slightly higher rates of agreement $(0.93)$ compared with those in supermarkets $(0 \cdot 88 ; P=0 \cdot 050)$.

\section{Cost per serving of fresh fruit and vegetables}

The estimated cost per week to meet the USDA's recommended servings of fruit and vegetables from fresh produce alone was completed on the basis of the methods of a previous study ${ }^{(29)}$. First, we computed the cost per serving on the basis of the unit audited using the USDA's recommended serving size of $\frac{1}{2}$ cup for fruit or vegetables ${ }^{(30)}$. The number of $\frac{1}{2}$ cup serving sizes per pound for each item was computed using the USDA's Food Buying Guide for Child Nutrition Programs ${ }^{(31)}$. This method accounts for waste accruing from cutting/preparation and from non-edible portions. For fruit items that were audited per piece, the following conversions were used for one serving size: $\frac{1}{5}$ of one whole avocado $^{(32)}, \frac{1}{2}$ mango $^{(33)}$ and $\frac{1}{8}$ of one whole pineapple. For vegetables audited per piece, we calculated $\frac{1}{2}$ cup serving as $\frac{1}{2}$ of one cucumber, $\frac{1}{2}$ ear of $\operatorname{corn}^{(33)}$ or $\frac{1}{10}$ of one bunch of celery (assuming ten stalks per bunch and one stalk equals $\frac{1}{2}$ cup) ${ }^{(33)}$. For lettuce, one cup was equal to one serving ${ }^{(33)}$; thus, we assumed that there were five one-cup servings per one bunch of green leaf lettuce, one head of iceberg lettuce or one bunch of spinach.

USDA guidelines recommend nine $\frac{1}{2}$ cup servings of fruit and vegetables per day on the basis of a $8368 \mathrm{~kJ}$ (2000 kcal)/d diet, which amounts to sixty-three $\frac{1}{2}$ servings/ week ${ }^{(30)}$. Servings should be distributed by subtype of fruit (citrus/berries/melons and other) and vegetables (deep green, deep yellow/orange, dry legumes, starchy and other) on the basis of the different nutrients provided. Since this audit did not specifically assess dry legumes, we excluded this group while computing recommended vegetable servings per week. As a result, we computed the cost to meet the required fifty-seven $\frac{1}{2}$ cup servings/week on the basis of an $8368 \mathrm{~kJ}(2000 \mathrm{kcal}) / \mathrm{d}$ diet. This included fourteen $\frac{1}{2}$ cup servings of citrus/berries/melon fruit and fourteen $\frac{1}{2}$ cup servings of other fruit types. For vegetables, this included six $\frac{1}{2}$ cup servings of dark green vegetables, four $\frac{1}{2}$ cup servings of deep yellow/orange vegetables, six $\frac{1}{2}$ cup servings of starchy vegetables and thirteen $\frac{1}{2}$ cup servings of other vegetables.

The median cost per serving for each fruit and vegetable subtype was computed per store. If an item was not available or if the cost was missing for an item in a store, the cost of that item was imputed using the median value over all stores within the same type. This median cost per serving was then multiplied by the number of recommended servings per week and compared by store type. A sensitivity analysis was also performed computing the cost per serving within each fruit and vegetable subgroup based only on the available items within each store. Cost per serving was not computed for canned or frozen produce, nor for dairy or ground beef, given the small sampling of possible products for these product types.

\section{Data analyses}

Descriptive summaries of fresh produce availability, variety, quality and cost per unit are presented overall and by store type (tiendas $v$. supermarkets). Availability and cost per unit of canned or frozen alternative to fresh produce are also described, as are availability and cost per unit of milk and ground beef. Distribution of categorical variables is compared by store type using Fisher's Exact test; continuous measures are presented as median with interquartile range (IQR) and compared with Wilcoxon rank-sum tests. All analyses were run using the $\mathrm{R}$ language for statistical computing, version $2 \cdot 9 \cdot 0$ (http:// www.R-project.org).

\section{Results}

\section{Store type}

Tiendas were significantly smaller in size than supermarkets. Tiendas had a median of 5 (IQR: 4-8) store aisles and 3 (IQR: 4-5) checkout stations per store compared with 12 (IQR: $8-17 ; P=0.003$ ) store aisles and 8 (IQR: $7-9 ; \quad P=0 \cdot 001)$ checkout stations in supermarkets. All tiendas and eight (53\%) supermarkets had an in-store butcher $(P=0 \cdot 020)$.

\section{Availability, variety and quality of fresb produce}

There was no significant difference in the total number of fresh fruit items offered per store by store type (Table 1). A median of 12 (IQR: 12-14) fruits were offered in tiendas compared with 13 (IQR: 12-14) offered in supermarkets $(P=0.533)$. Likewise, there was no significant difference in the total number of fresh vegetables offered in tiendas (median $=19, \quad \mathrm{IQR}=18-20) \quad$ compared with supermarkets (median $=19, \mathrm{IQR}=18-20 ; P=0 \cdot 9308$; Table 2 ). For only one fruit item (green seedless grapes) was availability significantly lower in tiendas compared with supermarkets (Table 1).

Overall, most stores offered 'good/high-' $v$. 'medium/ fair-quality' fruit items, with no significant differences in quality by store type. Quality ranged the most for pears. The only fruit item with a 'poor/low-quality' rating were strawberries, and this was in a supermarket. Likewise, most stores offered 'good/high-' $v$. 'medium/fair-quality' vegetable items, with no significant differences by store type (Table 2). Quality ranged the most for cauliflower, and this was the only vegetable item with a 'poor/low-quality' rating 
Table 1 Availability and quality of each fresh fruit item audited, by store type

\begin{tabular}{|c|c|c|c|c|c|c|c|c|}
\hline & \multicolumn{4}{|c|}{ Tiendas } & \multicolumn{4}{|c|}{ Supermarkets } \\
\hline & \multicolumn{2}{|c|}{ Availability } & \multicolumn{2}{|c|}{ Good/high quality* } & \multicolumn{2}{|c|}{ Availability } & \multicolumn{2}{|c|}{ Good/high quality* } \\
\hline & $\%$ & $n$ & $\%$ & $n$ & $\%$ & $n$ & $\%$ & $n$ \\
\hline \multicolumn{9}{|l|}{ Citrus/berries subgroup } \\
\hline Strawberries & 80 & 8 & 75 & 6 & 100 & 15 & 87 & 13 \\
\hline Oranges (naval) & 90 & 9 & 78 & 7 & 100 & 15 & 93 & 14 \\
\hline Honeydew melon & 80 & 8 & 100 & 8 & 100 & 15 & 100 & 14 \\
\hline Cantaloupe & 100 & 10 & 90 & 9 & 93 & 14 & 100 & 14 \\
\hline Watermelon (standard size) & 90 & 9 & 100 & 9 & 100 & 15 & 100 & 15 \\
\hline \multicolumn{9}{|l|}{ Other subgroup } \\
\hline Pineapple & 90 & 9 & 100 & 9 & 93 & 14 & 100 & 14 \\
\hline Grapes (green, seedless) & 50 & $5 \ddagger$ & 100 & 5 & 93 & $14 \ddagger$ & 93 & 13 \\
\hline Grapes (red, seedless) & 60 & 6 & 100 & 6 & 93 & 14 & 93 & 13 \\
\hline Pears (d'anjou) & 70 & 7 & 57 & 4 & 93 & 14 & 93 & 13 \\
\hline Peaches & 80 & 8 & 75 & 6 & 100 & 15 & 100 & 15 \\
\hline Apples (red delicious) & 100 & 10 & 100 & 10 & 100 & 15 & 100 & 15 \\
\hline Avocado (Hass) & 100 & 10 & 90 & 9 & 100 & 15 & 100 & 15 \\
\hline Mexican papaya & 80 & 8 & 88 & 7 & 87 & 13 & 100 & 13 \\
\hline Mangoes & 90 & 9 & 100 & 9 & 100 & 15 & 100 & 15 \\
\hline Bananas & 100 & 10 & 100 & 10 & 100 & 15 & 93 & 14 \\
\hline Number of items available per store & 12 & $12-14$ & & & 13 & $12-14$ & & \\
\hline
\end{tabular}

*Denominator is the number of stores with product available. Only one poor/low-quality rating: strawberries in one supermarket. All remaining items not included under good/high quality were rated as medium/fair. No significant differences were observed for any item (all $P>0.05$ ) with regard to quality between stores using Fisher's Exact test.

tData are presented as median and interquartile range; no difference in median number of items available by store type $(P=0.533)$.

$\ddagger$ Availability different by store type; $P<0.05$ using Fisher's Exact test.

Table 2 Availability and quality of each fresh vegetable item audited, by store type

\begin{tabular}{|c|c|c|c|c|c|c|c|c|}
\hline & \multicolumn{4}{|c|}{ Tiendas } & \multicolumn{4}{|c|}{ Supermarkets } \\
\hline & \multicolumn{2}{|c|}{ Availability } & \multicolumn{2}{|c|}{ Good/high quality* } & \multicolumn{2}{|c|}{ Availability } & \multicolumn{2}{|c|}{ Good/high quality* } \\
\hline & $\%$ & $n$ & $\%$ & $n$ & $\%$ & $n$ & $\%$ & $n$ \\
\hline \multicolumn{9}{|l|}{ Deep green subgroup } \\
\hline Lettuce (green leaf or romaine) & 90 & 9 & 89 & 8 & 93 & 14 & 100 & 14 \\
\hline Spinach & 80 & 8 & 88 & 7 & 93 & 14 & 100 & 14 \\
\hline \multicolumn{9}{|l|}{ Deep yellow subgroup } \\
\hline Yams (or sweet potatoes) & 90 & 9 & 100 & 9 & 93 & 14 & 100 & 14 \\
\hline Carrots & 100 & 10 & 100 & 10 & 100 & 15 & 100 & 15 \\
\hline \multicolumn{9}{|l|}{ Starchy subgroup } \\
\hline Potatoes (russet) & 100 & 10 & 100 & 10 & 100 & 15 & 100 & 15 \\
\hline Corn & 90 & 9 & 89 & 8 & 100 & 15 & 93 & 14 \\
\hline \multicolumn{9}{|l|}{ Other subgroup } \\
\hline Chile (Serrano) & 90 & 9 & 100 & 9 & 100 & 15 & 100 & 15 \\
\hline Green pepper & 90 & 9 & 89 & 8 & 93 & 14 & 100 & 14 \\
\hline Tomatillo & 90 & 9 & 100 & 9 & 93 & 14 & 100 & 14 \\
\hline Broccoli & 90 & 9 & 100 & 9 & 100 & 15 & 100 & 15 \\
\hline Cauliflower & 90 & 9 & 78 & 7 & 100 & 15 & 87 & 13 \\
\hline Tomatoes & 100 & 10 & 90 & 9 & 100 & 15 & 100 & 15 \\
\hline Celery & 100 & 10 & 100 & 10 & 100 & 15 & 100 & 15 \\
\hline Zucchini & 100 & 10 & 90 & 9 & 87 & 13 & 100 & 13 \\
\hline Lettuce (iceberg) & 100 & 10 & 80 & 8 & 100 & 15 & 100 & 15 \\
\hline Jicama & 100 & 10 & 100 & 10 & 87 & 13 & 100 & 13 \\
\hline Cucumbers & 90 & 9 & 100 & 9 & 100 & 15 & 100 & 15 \\
\hline Nopales & 90 & 9 & 100 & 9 & 67 & 10 & 100 & 10 \\
\hline Onions & 100 & 10 & 100 & 10 & 100 & 15 & 93 & 14 \\
\hline Cabbage (green) & 100 & 10 & 90 & 9 & 100 & 15 & 100 & 15 \\
\hline Number of items available per storet & 19 & $18-20$ & & & 19 & $18-20$ & & \\
\hline
\end{tabular}

*Denominator is the number of stores with product available. Only one vegetable item was rated as having poor/low quality: cauliflower in one tienda. All remaining items not included under good/high quality were rated as medium/fair. No significant differences were observed for any item (all $P>0.05$ ) with regard to quality between stores using Fisher's Exact test.

tData are presented as median and interquartile range; no difference in median number of items available by store type $(P=0 \cdot 931)$. 
in a tienda. There were no differences in fresh vegetable availability by store type.

\section{Cost of fresh produce}

Tiendas were more likely to offer produce at a lower cost per unit compared with supermarkets. For seven of the fruit items, tiendas offered lower costs per unit, and costs were equal by store type for the remaining eight items (Fig. 1). For eleven of the vegetable items, tiendas offered lower costs per unit, with costs being equal by store type for the remaining ten items (Fig. 2). Table 3 displays the potential savings per week based on the cost per serving in each subgroup to meet the USDA's recommended weekly servings of fruit and vegetables for one individual based on a diet of $8368 \mathrm{~kJ}(2000 \mathrm{kcal}) / \mathrm{d}$. Purchasing 1 week's worth of fresh produce to meet the recommended fifty-seven $\frac{1}{2}$ cup servings/week (excluding dry legumes) at a tienda would save a customer over \$US 3 compared with a similar purchase at a supermarket $(P<0 \cdot 001)$. Sensitivity analyses that computed the cost per serving based only on available items per store did not impact the results: costs remained significantly higher within supermarkets compared with tiendas for all subgroups.

Although no significant differences were found by store type with regard to cost for the canned or frozen alternatives to fresh produce (Table 4), availability of some items appeared lower in tiendas. This was significant only for frozen green beans $(P=0.023)$ and frozen $100 \%$ orange juice concentrate $(P=0 \cdot 005)$. There were no significant differences in availability for the remaining nine items.

\section{Availability of low-fat dairy and ground beef alternatives}

Whole, low-fat and skimmed milk was offered in nearly all stores, with no difference by store type (Table 5). The price per gallon of whole milk and of $1 \%$ fat milk was the same across store type; yet, skimmed milk was nearly 60 cents more per gallon in tiendas $(P=0 \cdot 005)$. The price per gallon appeared to decrease with decreasing fat content in supermarkets, whereas low-fat or skimmed milk appeared more expensive than whole milk in tiendas. Finally, less shelf space was devoted to skimmed/fat-free or $1 \%$ fat milk in tiendas $(16.5 \%)$ compared with supermarkets (35.7\%; $P=0 \cdot 002)$.

Tiendas and supermarkets were equally likely to offer regular ground beef or $15 \%$ fat ground beef; yet, $7 \%$ fat ground beef was available in only one of the ten tiendas compared with ten of the fifteen (67\%) supermarkets $(P=0 \cdot 012)$. There was the suggestion that regular ground beef was cheaper in tiendas compared with supermarkets (\$US $1.79 v$. \$US $2.50 ; P=0.059$ ); however, this difference was not statistically significant. When considering the increased cost of $15 \%$ fat compared with regular ground beef within each store, this price increase was \$US 1.20 in tiendas compared with \$US 0.90 in supermarkets, again a non-significant difference $(P=0 \cdot 276)$.

\section{Discussion}

The present study showed that Latinos who reported buying most of their groceries in a tienda do not appear to be at a disadvantage with respect to accessing a variety

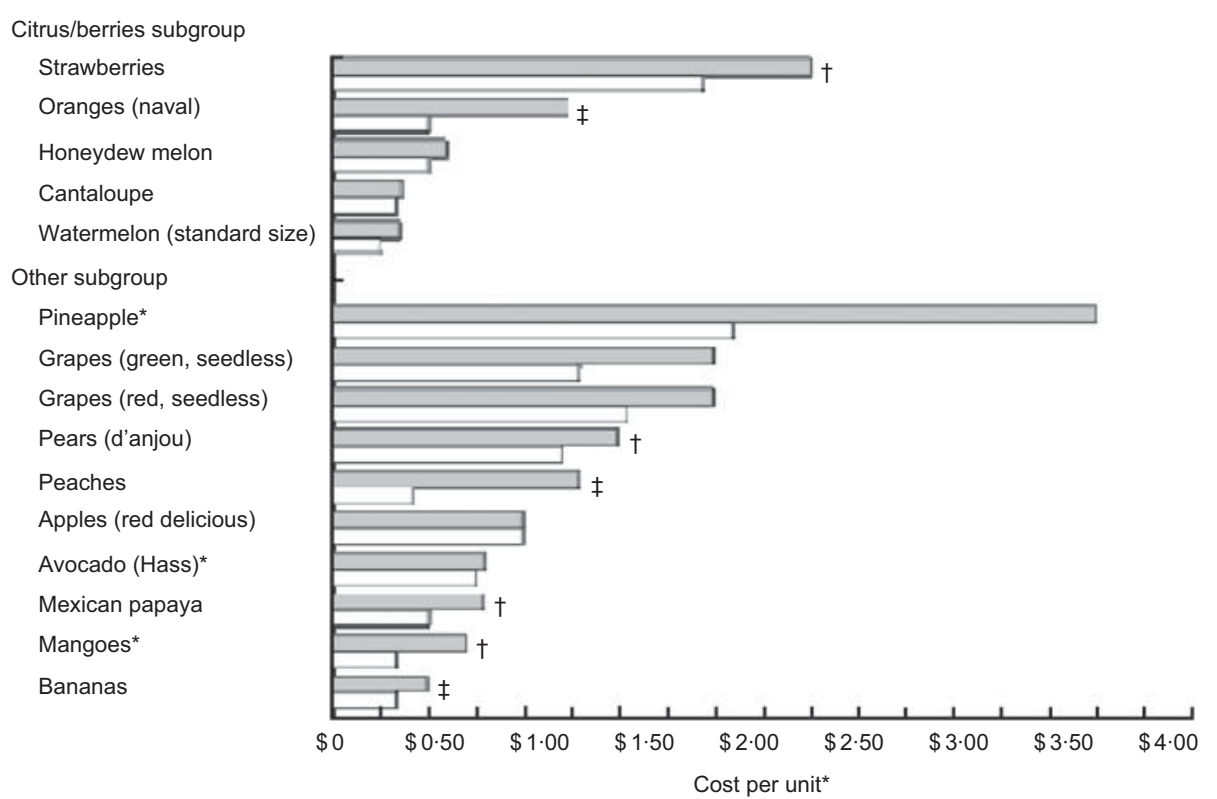

Fig. 1 Cost per unit* of fresh fruit by subtype and store type ( $\square$, supermarkets; $\square$, tiendas). All items were audited as cost per pound except ${ }^{(*)}$, where cost is per one whole item. Only five stores per each store type offered pineapple and no statistical comparisons were made. Significantly different by store type: $\dagger P<0.05$ and $\ddagger P<0.001$ 


Deep green subgroup
Lettuce (green leaf or romaine)
Spinach*
Deep yellow subgroup
Yams (or sweet potatoes)
Carrots
Starchy subgroup
Potatoes (russet)
Corn*
Other subgroup
Chile (Serrano)
Green pepper
Tomatillo
Broccoli
Cauliflower
Tomatoes
Celery*
Zucchini
Lettuce (iceberg) ${ }^{*}$
Jicama
Cucumbers*
Nopales
Onions
Cabbage (green)

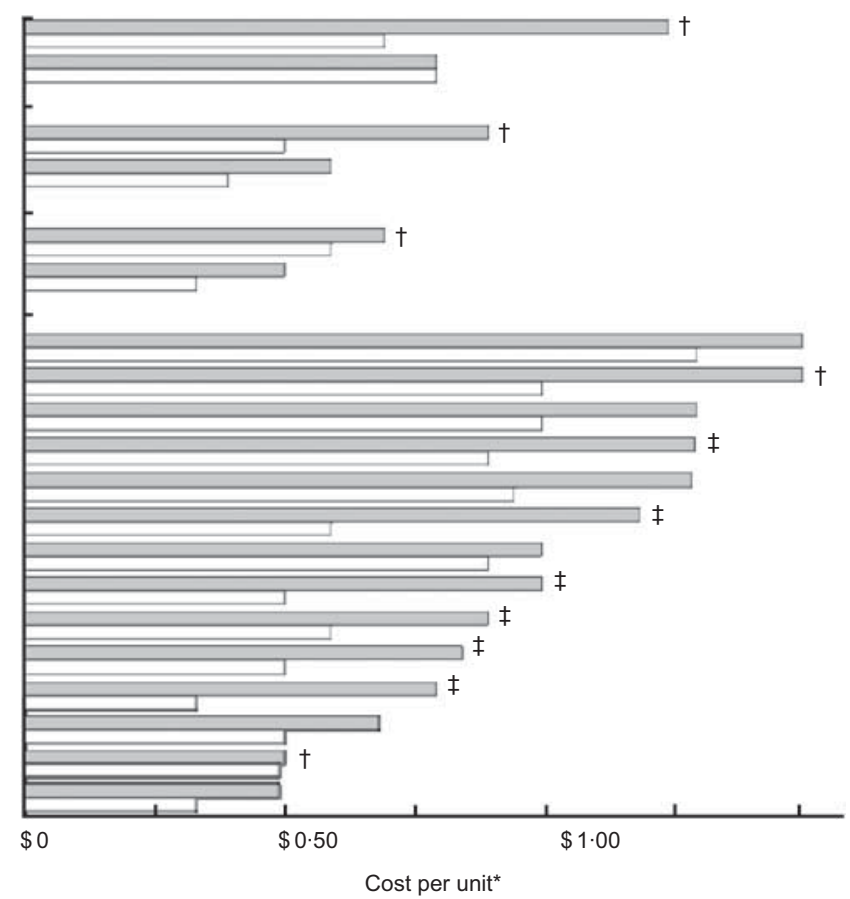

Fig. 2 Cost per unit* of fresh vegetables by subtype and store type ( $\square$, supermarkets; $\square$, tiendas). All items were audited as cost per pound except ${ }^{(*)}$, where cost is per one whole item. Significantly different by store type: $\uparrow P<0.05$ and $\ddagger P<0.001$

Table 3 Cost to meet the weekly recommended servings of fruit and vegetables from fresh produce based on a $8368 \mathrm{~kJ}(2000 \mathrm{kcal}) / \mathrm{d}$ diet, by store type

\begin{tabular}{|c|c|c|c|c|c|c|}
\hline & \multirow[b]{3}{*}{ Weekly servings ( $\frac{1}{2}$ cup servings) ${ }^{\star}$} & \multicolumn{4}{|c|}{ Weekly cost (\$US) } & \multirow[b]{3}{*}{ Wilcoxon $P$ value } \\
\hline & & \multicolumn{2}{|c|}{ Tiendas } & \multicolumn{2}{|c|}{ Supermarkets } & \\
\hline & & Median & IQR & Median & IQR & \\
\hline \multicolumn{7}{|l|}{ Fruit } \\
\hline Citrus & 14 & $2 \cdot 63$ & $2 \cdot 46-2 \cdot 96$ & $3 \cdot 63$ & $3 \cdot 00-4 \cdot 42$ & 0.007 \\
\hline Other & 14 & $2 \cdot 93$ & $2 \cdot 84-3 \cdot 07$ & $4 \cdot 43$ & $3 \cdot 85-5 \cdot 58$ & $<0.001$ \\
\hline Overall & 28 & $5 \cdot 68$ & $5 \cdot 17-5 \cdot 87$ & $8 \cdot 17$ & $6 \cdot 61-10 \cdot 36$ & $<0.001$ \\
\hline \multicolumn{7}{|l|}{ Vegetablest } \\
\hline Deep green & 6 & $0 \cdot 86$ & $0.79-1.04$ & $1 \cdot 25$ & $0 \cdot 89-1 \cdot 49$ & 0.063 \\
\hline Deep yellow & 4 & 0.48 & $0.45-0.55$ & $0 \cdot 77$ & $0.60-0.86$ & 0.007 \\
\hline Starchy & 6 & 0.87 & $0.74-0.97$ & $1 \cdot 22$ & $0.93-1.57$ & 0.019 \\
\hline Other & 13 & $1 \cdot 81$ & $1 \cdot 71-1 \cdot 84$ & $2 \cdot 54$ & $2 \cdot 27-3 \cdot 59$ & $<0 \cdot 001$ \\
\hline Overall & 29 & $4 \cdot 06$ & $3 \cdot 97-4 \cdot 20$ & $5 \cdot 54$ & $4 \cdot 61-7 \cdot 62$ & 0.001 \\
\hline \multicolumn{7}{|c|}{ Fruit and vegetablest } \\
\hline Overall & 57 & $9 \cdot 76$ & $9 \cdot 02-10 \cdot 40$ & $12 \cdot 95$ & $11 \cdot 46-17 \cdot 69$ & $<0.001$ \\
\hline
\end{tabular}

Cost computed within each store as the sum of the median cost per serving for each of the six fruit and vegetable subgroups, multiplied by the number of weekly servings per that subgroup.

*Based on nine $\frac{1}{2}$ cup servings of fruit and vegetables per day for a $8368 \mathrm{~kJ}(2000 \mathrm{kcal}) / \mathrm{d}$ diet, excluding dry legumes.

tExcludes dry legumes.

of high-quality, fresh produce. Importantly, the present study found that tiendas offered a lower cost for fresh produce as compared with supermarkets in the same region. These results are similar to a Chicago study that found less expensive produce in independent grocery stores or in independent supermarkets, compared with chain supermarkets, when comparing two Chicago neighbourhoods that varied by income and race ${ }^{(2)}$. It is to be noted that that study did not further classify stores by possible ethnic orientation.

The significant differences found in the present study would add up to a savings of over \$US 3/week for a diet of $8368 \mathrm{~kJ}(2000 \mathrm{kcal}) / \mathrm{d}$ and could reach over $\$ \mathrm{US}$ $12 /$ week for a four-person household at this energy intake. The recommended number of servings per person varies with age, gender and physical activity level, and, most 
Table 4 Availability and cost of selected canned or frozen fruit and vegetable substitutes for fresh produce, by store type

\begin{tabular}{|c|c|c|c|c|c|c|c|c|c|}
\hline & \multicolumn{4}{|c|}{ Tiendas } & \multicolumn{4}{|c|}{ Supermarkets } & \multirow{3}{*}{$\begin{array}{l}\text { Wilcoxor } \\
P \text { value }\end{array}$} \\
\hline & \multicolumn{2}{|c|}{ Availability } & \multicolumn{2}{|c|}{ Cost (\$US) } & \multicolumn{2}{|c|}{ Availability } & \multicolumn{2}{|c|}{ Cost (\$US) } & \\
\hline & $\%$ & $n$ & Median & IQR & $\%$ & $n$ & Median & IQR & \\
\hline \multicolumn{10}{|l|}{ Canned items } \\
\hline Corn $(15 \cdot 25 \mathrm{oz})$ & 100 & 10 & $0 \cdot 74$ & $0.59-0.79$ & 100 & 15 & $0 \cdot 79$ & $0.73-0.94$ & $0 \cdot 247$ \\
\hline Green beans ( $14.5 \mathrm{oz})$ & 100 & 10 & $0 \cdot 79$ & $0.72-0.88$ & 100 & 15 & $0 \cdot 79$ & $0.74-0.94$ & $0 \cdot 799$ \\
\hline Mandarin oranges $(11 \mathrm{oz})$ & 50 & 5 & 0.99 & $0.99-1.09$ & 87 & 13 & 0.98 & $0 \cdot 89-1 \cdot 00$ & $0 \cdot 150$ \\
\hline Peaches in heavy syrup ( $15.25 \mathrm{oz})$ & 80 & 8 & $1 \cdot 19$ & $1 \cdot 17-1 \cdot 32$ & 100 & 15 & $1 \cdot 29$ & $1 \cdot 12-1 \cdot 29$ & 0.794 \\
\hline Peaches in light syrup (15oz) & 70 & 7 & $1 \cdot 19$ & $0.99-1.29$ & 93 & 14 & $1 \cdot 27$ & $1 \cdot 06-1 \cdot 37$ & 0.625 \\
\hline Tomatoes (whole; $14.5 \mathrm{oz}$ ) & 80 & 8 & $0 \cdot 79$ & $0 \cdot 77-0 \cdot 89$ & 93 & 14 & $0 \cdot 89$ & $0.88-1.09$ & $0 \cdot 136$ \\
\hline \multicolumn{10}{|l|}{ Frozen items } \\
\hline Green beans $(1 \mathrm{lb})$ & 50 & $5^{\star}$ & $1 \cdot 39$ & $1 \cdot 09-1 \cdot 69$ & 93 & 14 & $1 \cdot 69$ & $1 \cdot 49-1 \cdot 89$ & $0 \cdot 208$ \\
\hline Peas $(1 \mathrm{lb})$ & 60 & 6 & 1.54 & $1 \cdot 34-1 \cdot 67$ & 87 & 13 & 1.59 & $1 \cdot 39-1 \cdot 69$ & 0.424 \\
\hline Mixed fruit $(1 \mathrm{lb})$ & 70 & 7 & $2 \cdot 19$ & $2 \cdot 04-2 \cdot 34$ & 93 & 14 & $2 \cdot 49$ & $2 \cdot 29-2 \cdot 59$ & $0 \cdot 166$ \\
\hline $100 \%$ Orange juice concentrate $(12 \mathrm{oz})$ & 50 & $5+$ & $1 \cdot 89$ & $1.59-1.99$ & 100 & 15 & $1 \cdot 29$ & $1 \cdot 19-1 \cdot 94$ & 0.273 \\
\hline $100 \%$ Fruit juice (12 oz) & 70 & 7 & $1 \cdot 89$ & $1.69-1.99$ & 100 & 15 & $1 \cdot 69$ & $1 \cdot 19-2 \cdot 14$ & 0.723 \\
\hline
\end{tabular}

IQR, interquartile range.

*Availability significantly different by store type $(P<0.05)$.

tAvailability significantly different by store type $(P<0.01)$.

Table 5 Availability and cost of low-fat milk and ground beef substitutes, by store type

\begin{tabular}{|c|c|c|c|c|c|c|c|c|c|}
\hline & \multicolumn{4}{|c|}{ Tiendas } & \multicolumn{4}{|c|}{ Supermarkets } & \multirow{3}{*}{$\begin{array}{l}\text { Wilcoxon } \\
P \text { value }\end{array}$} \\
\hline & \multicolumn{2}{|c|}{ Availability } & \multicolumn{2}{|c|}{ Cost (\$US) } & \multicolumn{2}{|c|}{ Availability } & \multicolumn{2}{|c|}{ Cost (\$US) } & \\
\hline & $\%$ & $n$ & Median & IQR & $\%$ & $n$ & Median & IQR & \\
\hline Whole milk ( 1 gallon) & 100 & 10 & $2 \cdot 99$ & $2 \cdot 99-3 \cdot 44$ & 100 & 15 & 3.09 & $3 \cdot 09-3 \cdot 29$ & 0.736 \\
\hline Low-fat milk (1\% fat; 1 gallon) & 80 & 8 & $3 \cdot 29$ & $2 \cdot 87-3 \cdot 49$ & 100 & 15 & $2 \cdot 99$ & $2 \cdot 87-3 \cdot 19$ & 0.238 \\
\hline Skimmed/fat-free milk ( 1 gallon) & 90 & 9 & 3.29 & $2 \cdot 99-3 \cdot 49$ & 93 & 14 & $2 \cdot 69$ & $2 \cdot 59-2 \cdot 92$ & 0.005 \\
\hline $\begin{array}{l}\text { Percentage of total milk shelf space devoted } \\
\text { to skimmed/fat-free or } 1 \% \text { milk }\end{array}$ & 100 & 10 & $16 \cdot 5$ & $9 \cdot 9-19 \cdot 8$ & 100 & 15 & $35 \cdot 7$ & $25 \cdot 5-38 \cdot 0$ & 0.002 \\
\hline Regular ground beef $(1 \mathrm{lb})^{*}$ & 80 & 8 & $1 \cdot 79$ & $1.59-2.09$ & 87 & 13 & $2 \cdot 50$ & $2 \cdot 18-2 \cdot 58$ & 0.059 \\
\hline $15 \%$ Fat ground beef $(1 \mathrm{lb})$ & 80 & 8 & $2 \cdot 94$ & $2 \cdot 49-2 \cdot 99$ & 87 & 13 & $3 \cdot 08$ & $2 \cdot 69-3 \cdot 99$ & $0 \cdot 130$ \\
\hline $7 \%$ Fat ground beef $(1 \mathrm{lb})$ & 10 & $1 \dagger$ & $3 \cdot 19$ & $\mathrm{~N} / \mathrm{A}$ & 67 & 10 & $4 \cdot 49$ & $3 \cdot 68-4 \cdot 79$ & - \\
\hline $\begin{array}{l}\text { Price difference: } 15 \% \text { fat ground beef minus } \\
\text { regular ground beef }\end{array}$ & 70 & 7 & $1 \cdot 20$ & $0 \cdot 85-1 \cdot 25$ & 73 & 11 & 0.90 & $0.50-1.25$ & 0.276 \\
\hline
\end{tabular}

IQR, interquartile range; N/A, not applicable.

${ }^{*}$ Regular ground beef allowed to contain up to $30 \%$ fat by US law.

tAvailability significantly different by store type $(P<0.05)$.

likely, meals prepared at home will not conform to the serving sizes used in the present analysis. However, these methods mirror those used in a USDA study ${ }^{(29)}$ and are consistent across store types. In addition, although two previous studies ${ }^{(2,3)}$ reported that the quality of produce was compromised in smaller markets located in lowerincome, largely African-American neighbourhoods, the quality of produce in the markets included in the present study was high and did not differ from that found in supermarkets. A strength of the present study is the use of three independent observers and the inclusion of three grades of quality ratings to assess the quality of thirty-five fresh produce items. Thus, these data provide strong evidence that quality of fresh produce is high in tiendas in this area of the USA

As an alternative to fresh produce, the USDA recommends the use of canned and frozen items as part of their Thrifty Food Plan ${ }^{(25)}$. These products can help reduce cost and extend the shelf life of the product, and customers may choose such items on the basis of personal choice. Again, customers in tiendas do not appear to be at a disadvantage in purchasing such products. No significant differences were found in the cost of any of the canned or frozen items by store type. Therefore, although we limited our computations of cost per serving to fresh produce, the inclusion of canned or frozen products would not materially change the differential in cost observed by store type. Admittedly, over $80 \%$ of all supermarkets had each of the products we looked at, whereas the availability appeared lower (50-70\%) for some of the products in tiendas. This may represent the ability of supermarkets to carry such products based simply on absolute size, or might even reflect a high turnover of products within tiendas given their smaller size and thus less shelf space. Interpreting these data must consider such limitations. However, taken together with the data on fresh produce, these results 
suggest that tienda customers have a range of products to meet their fruit and vegetable needs. Replication of these findings in other Latino communities is needed.

The USDA recommends the use of lower-fat milk and meat products ${ }^{(30)}$ and the availability of such alternatives is a key component of a store's healthy food availability index ${ }^{(27)}$. The present study did show that tienda customers may be at a disadvantage in their ability to opt for lower-fat alternatives to milk and ground beef. Specifically, lower-fat options for milk were more expensive in tiendas, and lean ground beef (7\%) was absent in all but one store. Again, this may reflect the differences in total shelf space available for such products, as well as product turnover or even consumer demand. However, these results are consistent with three other studies that measured the availability of lower-fat options within smaller grocery stores as compared with supermarkets in New York City ${ }^{(34)}$, Los Angeles and Sacramento ${ }^{(35)}$ and in communities located in Vermont and Arkansas ${ }^{(36)}$. Such limited availability of these products within tiendas could impair public health efforts to modify the dietary habits of individuals who shop in these stores. However, as all tiendas had an in-store butcher, further studies addressing the influence of a butcher on food choices is worth investigating.

The present study is based on a convenience sample of stores in one area of San Diego County, based on the main sources of groceries for families enrolled in a childhood obesity study. Although these stores represent $80 \%$ of those cited in the study, we cannot rule out the existence of other food outlets that different residents (namely, those without elementary-school-aged children) would shop at. However, after a review of the enumeration database used to verify these stores, we are confident that these twenty-five stores reflect the majority of outlets for groceries in this region. For example, of the seven chain supermarkets in the region, four were included in our study. It is important to note that the present study did not consider the relative location to other food outlets, such as convenience stores, liquor stores or even restaurants. As a result, these data are not intended to report on the complete food environment in this region. In addition, further studies are needed to link individual dietary choices and availability of products within grocery stores. This was not possible with these data because of the timing of baseline data collection and store audits. More complete studies are needed to address these subsequent steps. For now, we support the fact that these data reflect the availability and cost of various food items within stores that represent the primary source of household groceries for Latino families involved in the APN study.

These data report on a subset of products available within these grocery stores; the audit form was not specifically designed to capture all likely components of a standard market basket. Thus, we are unable to completely compare availability and cost for all recommended food types that constitute a healthy diet. For example, the audit form did not collect information on availability of poultry or fish. As one recent study reported a significant, negative relationship between store size and the cost of healthy food items as assessed using the Nutrition Environment Measures StudyStore instrument ${ }^{(36)}$, further work is needed to determine whether a similar relationship exists when considering a broader range of products within tiendas and supermarkets. However, this audit included thirty-six fresh produce items with regard to their availability, cost and quality, and a snapshot of availability for canned, frozen, dairy and ground beef items. The few potential disparities in the availability and cost of healthy food items reported here are encouraging in that customers who shop at tiendas may not be at a disadvantage in their ability to select healthy food options. Such findings could have implications for residents of these lower-income communities, not only for Latino families.

In summary, the present study highlights the importance of store classification when characterizing the food environment within a lower-income community. Comprehensive methods to classify stores on the basis of ethnic orientation and size can be used to identify important differences within broader store classifications such as supermarkets or grocery stores. Because tiendas are considerably smaller than supermarkets, tiendas would appear to contribute to an unsupportive food environment by being unable to offer a variety of quality, healthy food items at competitive cost. Taking a detailed audit, however, shows the positive influence tiendas can have in supporting a healthy diet. These data show that tiendas in Southern California are supportive environments for dietary interventions that promote increased fruit and vegetable consumption while identifying opportunities for growth, results that could have positive implications for all residents of these lowerincome communities and not simply for Latino families.

\section{Acknowledgements}

J.A.E. is a recipient of a Ruth L. Kirschstein National Research Service Award (NRSA) Institutional Training Grant (T32) awarded to San Diego State University by the National Institute of General Medical Sciences (5 T32 GM084896). The present study was supported by a grant to G.X.A. from San Diego State University's University Grants Program. The authors have no conflict of interest to declare. J.A.E. conducted data analysis, literature review and wrote the first draft of the manuscript; H.N.M. reviewed all analyses and reviewed and provided feedback on the manuscript; G.X.A. developed the store audit concept, led data collection efforts, reviewed all analyses and assisted with preparation of the manuscript.

\section{References}

1. Food Marketing Institute (2009) Supermarket Facts, Industry Overview. Arlington, VA: Food Marketing Institute; available at http://www.fmi.org/facts_figs/?fuseaction=superfact 
2. Block D \& Kouba J (2006) A comparison of the availability and affordability of a market basket in two communities in the Chicago area. Public Health Nutr 9, 837-845.

3. Lee RE, Heinrich KM, Medina AV et al. (2010) A picture of the healthful food environment in two diverse urban cities. Environ Health Insights 4, 49-60.

4. Kaufman PR, MacDonald JM, Lutz SM et al. (1997) Do the Poor Pay More for Food? Item Selection and Price Differences Affect Low-Income Household Food Costs. Agricultural Economic Report no. 759. Washington, DC: USDA, Food and Rural Economics Division, Economic Research Service.

5. Glanz K, Basil M, Maibach E et al. (1998) Why Americans eat what they do: taste, nutrition, cost, convenience, and weight control as influences on food consumption. $J$ Am Diet Assoc 98, 1118-1126.

6. Sturm R \& Datar A (2005) Body mass index in elementary school children, metropolitan area food prices and food outlet density. Public Health 119, 1059-1068.

7. Treuhaft S \& Karpyn A (2010) The Grocery Gap: Who Has Access to Healthy Food and Why It Matters. New York, NY: Policy Link and The Food Trust.

8. Morland K, Diez Roux AV \& Wing S (2006) Supermarkets, other food stores, and obesity: the atherosclerosis risk in communities study. Am J Prev Med 30, 333-339.

9. Moore LV, Diez Roux AV, Nettleton JA et al. (2008) Associations of the local food environment with diet quality - a comparison of assessments based on surveys and geographic information systems: the multi-ethnic study of atherosclerosis. Am J Epidemiol 167, 917-924.

10. Laraia BA, Siega-Riz AM, Kaufman JS et al. (2004) Proximity of supermarkets is positively associated with diet quality for pregnancy. Prev Med 39, 869-875.

11. Ogden CL, Carroll MD, Curtin LR et al. (2006) Prevalence of overweight and obesity in the United States, 1999-2004. JAMA 295, 1549-1555.

12. Harris MI, Flegal KM, Cowie CC et al. (1998) Prevalence of diabetes, impaired fasting glucose, and impaired glucose tolerance: the third National Health and Nutrition Examination Survey, 1998-1994. Diabetes Care 21, 518-524.

13. Cowie CC, Rust KF, Byrd-Holt DD et al. (2006) Prevalence of diabetes and impaired fasting glucose in adults in the U.S. population: National Health and Nutrition Examination survey 1999-2002. Diabetes Care 29, 1263-1268.

14. Pew Hispanic Center (2008) Demographic Profile of Hispanics in California. Washington, DC: Pew Research Center, The Pew Charitable Trusts; available at http:// pewhispanic.org/states/?stateid $=$ CA

15. Morland K, Wing S \& Diez Roux AV (2002) The contextual effect of the local food environment on residents' diets: the Atherosclerosis Risk in Communities study. Am J Public Health 92, 1761-1767.

16. National Council of La Raza (2010) A Closer Look at Latino Child Nutrition. Profiles of Latino Health. Washington, DC: National Council of La Raza. Series 4, Issue 4; available at http://www.nclr.org/images/uploads/pages/Jan12_Profiles_ Issue_4.pdf

17. Ayala GX, Mueller K, Lopez-Madurga E et al. (2005) Restaurant and food shopping selections among Latino women in Southern California. I Am Diet Assoc 105, 38-45.

18. Food Marketing Institute (2005) El Mercado 2004: A Perspective on U.S. Hispanic Shopping Behavior. Arlington, VA: Food Marketing Institute; available at http://www.fmi.org/ news_releases $/$ index.cfm?fuseaction $=$ mediatext\&id $=737$

19. San Diego Association of Governments (2000) Resources, Demographics \& Other Data, Current Estimates, Fast Facts.
San Diego, CA: SANDAG; available at http://www.sandag. org $/$ index.asp?subclassid $=52 \&$ fuseaction $=$ home.subclasshome

20. US Census Bureau (2000) American FactFinder, State and County QuickFacts. San Diego, CA. http://quickfacts.census. gov/qfd/states/06000.html

21. Ayala GX, Elder JP, Campbell NR et al. (2004) Correlates of body mass index and waist-to-hip ratio among Mexican women in the United States: implications for intervention development. Womens Health Issues 14, 155-164.

22. Swinburn B, Egger G \& Raza F (1999) Dissecting obesogenic environments: the development and application of a framework for identifying and prioritizing environmental interventions for obesity. Prev Med 29, 563-570.

23. Wang MC, Kim S, Gonzalez AA et al. (2007) Socioeconomic and food-related physical characteristics of the neighbourhood environment are associated with body mass index. J Epidemiol Community Health 61, 491-498.

24. Elder JP, Ayala GX, Campbell NR et al. (2006) Long-term effects of a communication intervention for Spanishdominant Latinas. Am J Prev Med 31, 159-166.

25. US Department of Agriculture (2000) Recipes and Tips for Healthy, Thrifty Meals. CNPP-11. Washington, DC: USDA, CNPP; available at http://www.cnpp.usda.gov/Publications/ FoodPlans/MiscPubs/FoodPlansRecipeBook.pdf

26. US Department of Agriculture (2011) Fact Sheets, Meat Preparation. Ground Beef and Food Safety. Washington, DC: USDA, FSIS; available at http://www.fsis.usda.gov/ factsheets/Ground_Beef_and_Food_Safety/index.asp

27. Glanz K, Sallis JF, Saelens BE et al. (2007) Nutrition Environment Measures Survey in Stores (NEMS-S): development and evaluation. Am J Prev Med 32, 282-289.

28. Fienstein AR \& Cicchetti DV (1990) High agreement but low kappa: I. The problems of two paradoxes. J Clin Epidemiol 43, 543-549.

29. Reed J, Frazao E \& Itskowitz R (2004) How Much do Americans Pay for Fruits and Vegetables? Agricultural Information Bulletin no. 790. Washington, DC: USDA, FRED, ERS.

30. US Department of Health and Human Services (2005) Food groups to encourage. In Dietary Guidelines for Americans. Washington, DC: Office of Disease Prevention and Health Promotion, Office of the Assistant Secretary for Health, Office of the Secretary, US Department of Health and Human Services; available at http://www.health.gov/dietaryguidelines/ dga2005/document/html/chapter5.htm

31. US Department of Agriculture (2008) Food Buying Guide for Child Nutrition Programs. Washington, DC: USDA, FNS; available at http://www.fns.usda.gov/tn/resources/food buyingguide.html

32. Haas Avocado Board (2010) Avocado nutrition facts and label. http://www.avocadocentral.com/nutrition/avocadonutrition-health-facts-label (accessed September 2010).

33. Centers for Disease Control and Prevention (2010) Fruits and Veggies Matter, What Counts as a Cup, More Examples. Washington, DC: CDC; available at http://www.fruitsand veggiesmatter.gov/what/examples.html

34. Wechsler H, Basch CE, Zybert $\mathrm{P}$ et al. (1995) The availability of low-fat milk in an inner-city Latino community: implications for nutrition education. Am J Public Health 85, 1690-1692.

35. Jetter KM \& Cassady DL (2006) The availability and cost of healthier food alternatives. Am J Prev Med 30, 38-44.

36. Krukowski RA, West DS, Harvey-Berino J et al. (2010) Neighborhood impact on healthy food availability and pricing in food stores. J Community Health 35, 315-320. 